\title{
Kandungan Air Daun Padi Lokal Sulawesi Utara terhadap Kekeringan yang Diinduksi dengan Polietilen Glikol 8000 (Leaf Water Content of North Sulawesi Local Rice under Polyethylene-Glycol- 8000 -Induced Drought)
}

\author{
Monalisa Pirade ${ }^{1)}$, Nio Song Ai ${ }^{1)}$, Parluhutan Siahaan ${ }^{1)}$ \\ 1)Program Studi Biologi, Jurusan Biologi FMIPA UNSRAT Manado, 95115 \\ *Email korespondensi: niosongai@unsrat.ac.id \\ Diterima 1 Februari 2018, diterima untuk dipublikasi 28 Februari 2018
}

\begin{abstract}
Abstrak
Perubahan iklim menjadi salah satu penyebab terjadinya kekeringan dan kondisi ini dapat menurunkan produksi padi. Polietilen glikol (PEG) mampu menurunkan potensial air dalam larutan, sehingga dapat digunakan untuk menginduksi kekeringan. Penelitian ini bertujuan untuk mengkaji ada tidaknya perbedaan respons fisiologis berdasarkan kandungan air daun pada tanaman padi lokal Sulawesi Utara yang mengalami kekeringan dengan induksi PEG 8000. Hasil penelitian ini menunjukkan bahwa faktor varietas (Superwin, Burungan, Ombong, dan Temo), faktor konsentrasi PEG 8000 (potensial air medium 0, -0,25 dan-0,5 MPa), faktor waktu perlakuan (0,6 dan 12 jam), interaksi antara faktor varietas dan konsentrasi $P E G$, interaksi antara faktor varietas dan waktu perlakuan, interaksi antara faktor konsentrasi dan waktu perlakuan, interaksi antara faktor varietas, konsentrasi PEG, dan waktu perlakuan dalam cekaman kekeringan tidak menyebabkan perbedaan kandungan air daun yang nyata. Dalam penelitian ini kandungan air daun tidak dapat dijadikan sebagai indikator respons fisiologis pada keempat varietas padi lokal Sulawesi Utara terhadap cekaman kekeringan.

Kata kunci: cekaman kekeringan, PEG, kandungan air daun, padi lokal Sulawesi Utara
\end{abstract}

\begin{abstract}
Climate change can result in drought and this condition can reduce rice production. Polyethylene glycol (PEG) decreases the water potential in the nutrient solution, therefore, it can be used to induce drought. The purpose of this research was to evaluate physiological response of North Sulawesi local rice under PEG 8000induced drought based on the leaf water content. The results of this study indicated that varieties factor (Superwin, Ombong, Burungan and Temo), the factor of PEG 8000 concentration (medium water potential -0.25 and $-0.5 \mathrm{MPa}$ ), the treatment period factor (0, 6 and 12 hours), the interaction between varieties and PEG 8000 concentration, interaction between varieties and treatment period, the interaction between PEG 8000 concentration and treatment period, interaction among varieties, PEG 8000 concentration and treatment period under drought did not result in significant differences in leaf water content. This study showed that leaf water content was not able to be the physiological indicator in these four North Sulawesi local rice varieties under drought.

Keywords: Drought, PEG, leaf water content, North Sulawesi local rice
\end{abstract}




\section{PENDAHULUAN}

Perubahan iklim merupakan salah satu penyebab terjadinya kekeringan (Tao et al. 2006). Awal dari terjadinya kekeringan disebabkan karena berkurangnya curah hujan di bawah normal pada satu musim. Berkurangnya pasokan air permukaan dan air tanah yang menyebabkan kebutuhan air bagi tanaman tidak terpenuhi disebut sebagai kondisi kekeringan pertanian (Sujinah et al. 2016). Kekeringan akan berdampak buruk terhadap produktivitas dan produksi pangan dunia (Wood 2005).

Kandungan air daun merupakan parameter yang dapat diukur sebagai respons fisiologis tanaman yang mengalami kekeringan ( $\mathrm{Li}$ et al. 2006). Kekeringan akan mempengaruhi kandungan air daun, yaitu kandungan air daun padi lokal Sulawesi Utara (Superwin, Burungan, Temo dan Ombong) yang tidak diairi sampai kapasitas lapang lebih kecil daripada yang diairi $100 \%$ kapasitas lapang (Koda et al. 2017).

Senyawa polietilen glikol (PEG) dapat menyebabkan penurunan potensial air. Sifat PEG yang demikian dapat dimanfaatkan untuk melakukan simulasi penurunan potensial air, sehingga sering digunakan untuk menguji ketahanan suatu tanaman terhadap kekeringan (Lestari 2006). Semakin besar berat molekul PEG, semakin kecil kemungkinan senyawa tersebut diserap oleh sel tanaman sehingga hanya menurunkan potensial air pada media dan kemungkinan terjadinya keracunan lebih kecil (Pratiwi 2016). Induksi PEG 6000 pada tanaman kacang tanah dapat menghambat pertumbuhan tanaman (Rahayu et al. 2006).

Penelitian ini bertujuan untuk mengkaji ada tidaknya perbedaan respons fisiologis pada fase vegetatif berdasarkan kandungan air daun pada tanaman padi lokal Sulut yang mengalami kekeringan dengan induksi PEG 8000 pada potensial medium $0,-0,25$ dan $-0,5 \mathrm{MPa}$.

(PA)

\section{METODE}

Penelitian ini telah dilaksanakan selama delapan minggu di rumah kaca di Kelurahan Tingkulu, Manado, Sulawesi Utara dan empat minggu di Laboratorium Ekologi Jurusan Biologi FMIPA Universitas Sam Ratulangi.

Bahan yang digunakan dalam penelitian ini adalah padi lokal Sulawesi Utara (varietas Temo, Ombong, Burungan, dan Superwin), dan polietilen glikol (PEG) 8000. Penelitian yang dilakukan merupakan percobaan faktorial dalam Rancangan Acak Kelompok (RAK) dengan tiga macam perlakuan kekeringan yang diinduksi dengan PEG 8000 dengan potensial air (PA) medium $0,-0,25$ dan $-0,5 \mathrm{MPa}$ yang dibuat dengan cara menambahkan 0, 135 dan $198 \mathrm{~g}$ PEG 8000 ke dalam 1 L larutan hidroponik Nutrisi Hidroponik AB Mix Minimax®. Tahapan kerja dalam penelitian ini meliputi seleksi benih, perkecambahan dan pemeliharaan tanaman, perlakuan kekeringan, pengukuran parameter fisiologis, dan analisis data. Benih padi diseleksi dengan cara direndam dalam air garam yang terlebih dahulu diapungkan telur (pertanda konsentrasi air garam sudah cukup untuk rendaman benih) selama 2 jam. Benih disterilkan dengan menggunakan pemutih komersial $2 \%$ dengan bahan aktif 5,25\% $\mathrm{NaClO}$ selama 2 menit dengan 3 kali ulangan, lalu dibilas dengan air. Selanjutnya benih dikecambahkan pada media tanam yang diisi tanah dan pupuk NPK $(6 \mathrm{~g}$ pupuk NPK dalam $7 \mathrm{~kg}$ tanah), kemudian media disiram dengan air sampai kapasitas lapang. Padi disiram dengan campuran air 
dan campuran pupuk Gandasil D (10 g pupuk Gandasil D dalam $10 \mathrm{~L}$ air) selama 4 minggu sampai tanaman mencapai tahap 4 daun yang berkembang penuh (modifikasi Nio dan Ludong 2013). Sebelum perlakuan, tanaman padi dibersihkan dan dipindahkan ke dalam gelas plastik yang berisi $100 \mathrm{~mL}$ campuran larutan hidroponik Nutrisi Hidroponik AB Mix Minimax®. Kemudian tanaman disangga menggunakan spons di bagian mulut gelas. Tanaman diadaptasikan selama 1 minggu, menggunakan shaker berkecepatan 50 opm di dalam ruangan dengan suhu $25^{\circ} \mathrm{C}$ dengan disinari cahaya lampu (cool white 36 Watt, 2880 lumen) selama 12 jam per hari. Perlakuan kekeringan dilakukan selama 12 jam pada larutan PEG 0, 0,25 serta $-0,5 \mathrm{MPa}$ dengan menggunakan shaker berkecepatan 50 opm di dalam ruangan dengan suhu $25^{\circ} \mathrm{C}$ dengan disinari cahaya lampu (cool white 36 Watt, 2880 lumen). Pengambilan sampel (Tabel 1) dilakukan sebanyak 3 kali yaitu pada jam ke-0 (sebelum perlakuan dimulai), 6 dan 12 jam setelah perlakuan (modifikasi Nio et al. 2011b).

Tabel 1. Waktu pengambilan sampel daun padi yang mengalami kekeringan dengan perlakuan PEG 8000

\begin{tabular}{cccc}
\hline & \multicolumn{3}{c}{$\begin{array}{c}\text { Waktu Pengamatan } \\
\text { (Jam) }\end{array}$} \\
\cline { 2 - 4 } PEG (MPa) & $\mathbf{0}$ & $\mathbf{6}$ & $\mathbf{1 2}$ \\
\hline 0 & $\checkmark$ & $\checkmark$ & $\checkmark$ \\
$-0,25$ & & $\checkmark$ & $\checkmark$ \\
$-0,5$ & & $\checkmark$ & $\checkmark$ \\
\hline
\end{tabular}

Daun padi dari tiap varietas dan tiap perlakuan dipotong sebanyak 10 potongan masing-masing berukuran $1 \times 1 \mathrm{~cm}$, dimasukkan ke dalam botol timbang lalu ditimbang untuk diketahui berat segar (BS). Seluruh potongan daun diletakkan dalam oven kering pada suhu $70^{\circ} \mathrm{C}$ selama 48 jam dan ditimbang berat keringnya (BK). Kandungan air daun (KA) dihitung dengan menggunakan rumus $\mathrm{KA}(\mathrm{mL} / \mathrm{g}$ berat kering $)=(\mathrm{BS}-$ BK)/BK (modifikasi Nio et al. 2011a). Data yang diperoleh dianalisis dengan ANAVA dan dilanjutkan dengan uji Duncan 5\% (Hendriyani dan Setiari 2009).

\section{HASIL DAN PEMBAHASAN}

Air merupakan komponen penting untuk pertumbuhan dan perkembangan tanaman. Sekitar 85$90 \%$ dari bobot segar sel-sel dan jaringan tanaman adalah air (Maynard dan Orcott 1987). Kebutuhan air setiap tanaman berbeda, tergantung pada jenis tanaman dan fase pertumbuhannya. Oleh karena itu proses fisiologis pada tanaman tersebut akan terganggu saat kekurangan air (Solichatun et al. 2005). Tanaman yang mengalami kekeringan akan kehilangan turgor dalam sel sehingga dapat menurunkan kandungan air daun. Hal ini terjadi karena tanaman berusaha untuk menurunkan dampak kehilangan air secara berlebihan yang disebabkan oleh kekurangan air tersebut (Fisher et al. 2003). Beberapa penelitian telah dilakukan untuk mengevaluasi kandungan air daun terhadap kekeringan diantaranya kelapa sawit yang tidak disirami selama tujuh sampai 14 hari (Mathius et al. 2001), pada gandum yang tidak disirami selama 36 hari (Nio et al. 2011a) dan pada padi lokal Sulut yang 
tidak disirami air selama 14 hari (Koda et al. 2017).

Analisis sidik ragam

menunjukkan bahwa faktor varietas (Superwin, Burungan, Ombong, dan Temo), faktor konsentrasi PEG 8000 (PA medium $0,-0,25$ dan $-0,5 \mathrm{MPa}$ ), faktor waktu perlakuan $(0,6$ dan 12 jam), interaksi antara faktor varietas dan konsentrasi PEG, interaksi antara faktor varietas dan waktu perlakuan, interaksi antara faktor konsentrasi dan waktu perlakuan, interaksi antara
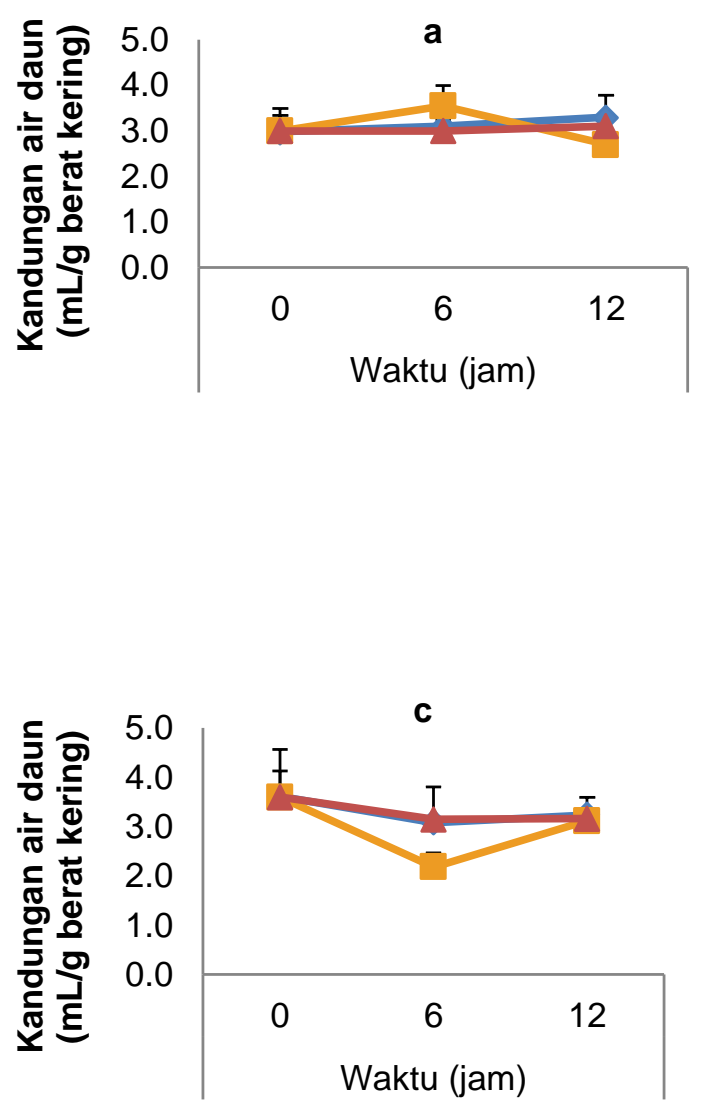

faktor varietas, konsentrasi PEG, dan waktu perlakuan dalam cekaman kekeringan tidak menyebabkan perbedaan kandungan air daun yang nyata (Gambar 1). Oleh sebab itu tidak dilakukan uji lanjut. Hal ini menunjukkan bahwa cekaman kekeringan yang diinduksi dengan PEG 8000 sampai 12 jam tidak memengaruhi kandungan air daun padi varietas Superwin, Burungan, Ombong, dan Temo pada fase vegetatif.
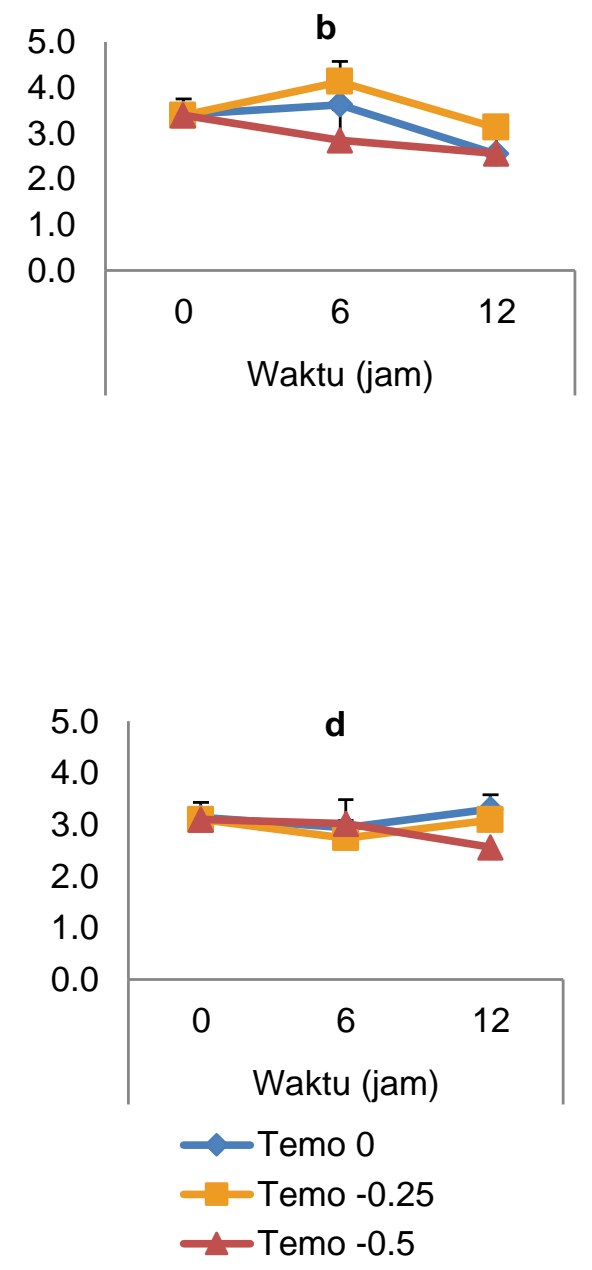

Gambar 1. Kandungan air daun ( $\mathrm{mL} / \mathrm{g}$ berat kering) pada daun padi varietas Superwin (a), Burungan (b), Ombong (c) dan Temo (d) setelah mengalami cekaman kekeringan yang diinduksi dengan PEG 8000 (PA $0,-0,25$ dan $-0,5 \mathrm{MPa}$ ) selama 0 , 6 dan 12 jam. 
Penelitian Koda et al. (2017) pada padi lokal Sulut yang diberi perlakuan kekeringan selama 14 hari menunjukkan kandungan air daun sebesar $0,79 \mathrm{~mL} / \mathrm{g}$ berat kering dibandingkan dengan kontrol sebesar $0,84 \mathrm{~mL} / \mathrm{g}$ berat kering. Mathius et al. (2001) melaporkan bahwa kandungan air daun kelapa sawit yang tidak disirami selama 7-14 hari adalah 65,52 dan $70,67 \mathrm{~mL} / \mathrm{g}$ berat kering berturut-turut pada hari ke-14 dan ke7 dibandingkan dengan $74,97 \mathrm{~mL} / \mathrm{g}$ pada kontrol. Nio et al. (2011a) menunjukkan bahwa kandungan air daun gandum varietas Hartog yang tidak disirami selama 36 hari pada fase reproduktif $50 \%$ lebih kecil daripada yang diairi sampai kapasitas lapang. Dalam penelitian ini kandungan air daun tidak bisa dipakai sebagai indikator adanya kekeringan pada padi lokal Sulut karena perlakuan kekeringan yang diberikan diinduksi dengan PEG 8000 dan berbeda dengan penelitian-penelitian yang lain yang memberikan perlakuan kekeringan dengan cara tidak disirami. Di samping itu periode kekeringan dalam penelitian ini hanya sampai 12 jam dan jauh lebih singkat dibandingkan dengan penelitian Mathius et al. (2001), Nio et al. (2011a), dan Koda et al. (2017).

\section{KESIMPULAN}

Perlakuan kekeringan yang diinduksi dengan PEG 8000 pada potensial air medium $-0,25$ dan $-0,5$ MPa dalam periode 12 jam tidak menyebabkan perbedaan kandungan air daun, sehingga kandungan air daun tidak dapat dijadikan indikator respons fisiologis pada keempat varietas padi lokal Sulawesi Utara terhadap cekaman kekeringan.

\section{DAFTAR PUSTAKA}

Fisher KS, Fukai (2003) How Rice Responds to Drought. Breeding Rice for Drought-Prone Environment. IRRI, Philippine

Hendriany IS, Setiari N. Kandungan Klorofil dan Pertumbuhan Kacang Panjang (Vigna sinensis) pada Tingkat Penyediaan Air yang Berbeda (2009) Jurnal Sains 17(3):145150

Koda M, Nio SA, Siahaan, P (2017) Respon Fisiologi Tanaman Padi Lokal Sulut pada Fase Vegetatif yang Mengalami Rendaman dan Kekurangan Air. Jurnal Bioslogos 7(1):23-26

Lestari ED (2006) Identifikasi Somaklon Padi Gahagmungkur, Towuti dan IR 64 Tahan Kekeringan Menggunakan Polietilen Glikol. Jurnal Balai Besar Penelitian Bioteknologi dan Sumber Daya Genetik Pertanian 34(2):71-78

Li R, Guo P, Baum M, Grando S, Ceccarelli S (2006) Evaluation of Chlorophyll Content and Fluorescence Parameters as Indicators of Drought Tolerance in Barley. Agricultural Siences in China 5(10):751-757

Mathius NT, Wijana G, Guharja E, Aswidinnoor $H$, Yahya $S$, Subronto (2001) Respon Tanaman Kelapa Sawit (Elaeis guineensis) terhadap Cekaman Kekeringan. Jurnal Penelitian Bioteknologi Perkebunan 69(2):29-45

Maynard GH, Orcot DM (1987) The Physiology of Plants under Stress. John Willey and Sons, Inc, New York

Nio SA, Cawthray GR, Wade LJ, 
Colmer TD (2011a) Pattern of Solutes Accumulated During Leaf Osmotic Adjustment as Related to Duration of Water for Wheat at the Reproductive Stage. Plant Physiol and Biochem 49:1126-1137

Nio SA, Colmer TD, Wade LJ, Cawthray G (2011b) Osmotic Adjustment and Solutes Accumulation in Leaves of Wheat (Triticum aestivum L.) during Water Deficit. Journal of Mathematics and Sciences 16:43-48

Nio SA, Ludong DPM (2013) Comparing the Drought Tolerance of Local Rice Cultivar Superwin with Other Cultivars in North Sulawesi Province Based on Dry Matter Partitioning. $4^{\text {th }}$ International Conference of Global Resource Conservation, Brawijaya University

Pratiwi AR (2016) Kajian Efek Polietilen Glikol (PEG) 6000 terhadap Cekaman Kekeringan Planlet Kedelai (Glycine max L.) Varietas Tanggamus secara in vitro. Skripsi. FMIPA Universitas Lampung
Rahayu E, llyas S, Sudarsono (2006) Seleksi In Vitro Embrio Somatik Kacang Tanah pada Medium dengan Polietilen Glikol untuk Simulasi Kondisi Cekaman Kekeringan. Jurnal Biosfera 23(1):16-23

Solichatun, Anggarwulan E, Mudyantini W (2005) Pengaruh Ketersediaan Air terhadap Pertumbuhan dan Kandungan Bahan Aktif Saponin Tanaman Ginseng Jawa (Talinum paniculatum Gaertn). Jurnal Biofarmasi 3(2):47-51

Sujinah, Jamil A (2016) Mekanisme Respon Tanaman Padi terhadap Cekaman Kekeringan dan Varietas Toleran. Jurnal Iptek Tanaman Pangan 11(1):1-7

Tao H, Brueck H, Dittert K, Kreye C, Lin S, Sattelmacher B (2006) Growth and Yield Formation for Rice (Oryza sativa L.) in the Water-saving Ground Cover Rice Production System. Field Crops Research 95(1):1-12

Wood AJ (2005) Plant Abiotic Stress. Blackweell Publishing, India 